\title{
COVID-19 Pandemisinde Bireylerin Ağrı, Fiziksel Aktivite ve Problemli İnternet Kullanımı Düzeyleri Arasındaki ilişskiler
}

\section{Relationship between Individuals' Levels of Pain, Physical Activity and Problematic Internet Use in the COVID-19 Pandemic}

\author{
Anıl Özüdoğru 1(D), Önder Baltacı 2(D), Muhammed Samed Dalakçı ’(D), \\ Faruk Akbulut ${ }^{4}$ (D) \\ 1. Kırşehir Ahi Evran Üniversitesi, Fizik Tedavi ve Rehabilitasyon Yüksekokulu, Fizyoterapi ve Rehabilitasyon Bölümü, Kırşehir \\ 2. Kırșehir Ahi Evran Üniversitesi, Eğitim Fakültesi, Rehberlik ve Psikolojik Danıșmanlık Anabilim Dalı, Kırșehir \\ 3. Kırşehir Ahi Evran Üniversitesi, Sağlık Hizmetleri Meslek Yüksekokulu, Terapi ve Rehabilitasyon Bölümü, Kırşehir \\ 4. Necmettin Erbakan Üniversitesi, Eğitim Bilimleri Enstitüsü, Rehberlik ve Psikolojik Danışmanlık Bilim Dalı, Konya
}

\section{Abstract}

Objective: The aim of this research is to examine the role of sex with physical activity and problematic internet use as predictors of pain levels caused by individuals ' use of technology during the covid-19 pandemic.

Method: The research was carried out by relational screening method. The participants of the study are 296 adult individuals over the age of 18 living in Turkey, 198 of whom are female (66.9\%) and 98 of whom are male (33.1\%), who use the internet actively. In the study, "Problematic Internet Use Scale-Short Form-6", "International Physical Activity Questionnaire - Short Form" and "Personal Information Form" were used.

Results: A negatively significant association was found between pain levels and physical activity levels caused by individuals ' use of technology during the COVID-19 pandemic, while a positively significant association was found between problematic internet usage levels. In addition, gender, physical activity, and problematic internet use variables were found to together explain $18.3 \%$ of the total variance in pain caused by technology use.

Conclusion: During the pandemic period, physical activity, problematic internet use and gender factors were found to have an important place in the level of pain caused by individuals ' use of technology.

Keywords: Pain, physical activity, problematic internet use, COVID-19, gender

Öz

Amaç: Bu araştırmanın amacı, COVID-19 pandemisi döneminde bireylerin teknoloji kullanımlarından kaynaklı ağıı düzeylerinin yordayıcıları olarak fiziksel aktivite ve problemli internet kullanım düzeyi ile cinsiyetin rolünü incelemektir.

Yöntem: Araştırma, ilişkisel tarama yöntemi ile gerçekleştirilmiştir. Araştırmanın katılımcılarını, Türkiye'de yaşayan 18 yaş üzeri ve aktif internet kullanan 198'i kadın (\%66.9) 98'i erkek olmak üzere (\%33.1) 296 yetişkin birey olușturmaktadır. Araştırmada; "Problemli İnternet Kullanımı Ölçeği-Kısa Form-6", "Uluslararası Fiziksel Aktivite Anketi - Kısa Form" ve "Kişisel Bilgi Formu" kullanılmıştır.

Bulgular: Bireylerin COVID-19 pandemisi döneminde teknoloji kullanımlarından kaynaklı ağrı düzeyleri ile fiziksel aktivite düzeyleri arasında negatif yönde anlamlı bir ilișki bulunurken, problemli internet kullanımı düzeyleri arasında pozitif yönde anlamlı bir ilişki bulunmuştur. Ayrıca cinsiyet, fiziksel aktivite ve problemli internet kullanımı değişkenleri birlikte, teknoloji kullanımından kaynaklanan ağrıdaki toplam varyansın \%18.3'ünü açıkladığı görülmüştür.

Sonuç: Pandemi döneminde bireylerin teknoloji kullanımlarından kaynaklanan ağrı düzeylerinde fiziksel aktivite, problemli internet kullanımı ve cinsiyet faktörlerinin önemli bir yere sahip olduğu görülmüştür.

Anahtar kelimeler: Ağrı, fiziksel aktivite, problemli internet kullanımı, COVID-19, cinsiyet 


\section{Giriş}

COVID-19 pandemisi son bir yıldır bütün Dünya'yı etkisi altına alarak insanların yaşamlarını büyük oranda etkilemiştir. IIlk olarak Çin'in Wuhan kentinde ortaya çıkan bu salgın daha sonra hızlı bir şekilde bütün Dünya'ya yayılmış ve Dünya Sağlık Örgütü (DSÖ) bu durumu bir pandemi olarak nitelendirmiştir (1). Bu durum birçok ülkeyi salgının yayılım hızını azaltmak için önlemler almaya teşvik etmiştir. Illk vakanın Mart 2020'de görüldüğü Türkiye'de sokağa çıkma kısıtlamaları, uzaktan eğitime geçilmesi, maske takma zorunluluğu, esnek çalışma ve seyahat kısıllamaları gibi birçok önlem alınarak pandemiyle mücadele edilmek istenmiştir (2). Alınan bu önlemler salgının yayılım hızını azaltmada başarılı olmasına karşın bireylerin farklı yaşamsal alanlarında sorunlar oluşturmaya başlamıştır.

Bireylerin ev içerisinde daha fazla kalmaları ve hareketsiz bir yaşamın ortaya çıkması fiziksel, psikolojik ve sosyal yaşam alanlarında bireylerin çeșitli sorunlar yaşamalarına neden olmuștur $(3,4)$. Yapılan araştırmalarda, ülkelerin aldıkları önlemlerin bireylerin koronavirüs hastalığına yakalanmalarını engellemekte başarılı olduğunu ancak bu önlemlerin depresyon (5,6), kaygı (7), stres (8), teknoloji bağımlılığı $(9,10)$, kilo alma (11), obezite (12), sağlıksız beslenme (13), akademik $(14,15)$ ve kariyer ile ilgili problemler (16-18) gibi çeşitli sorunları ortaya çıkardığı görülmüştür. Özellikle bireylerin pandeminin ortaya çıkışıyla birlikte mesleki veya akademik yaşamlarını teknolojik araçlarla sürdürmeleri hareketsiz kalma, uygun olmayan postür ve masa düzeni gibi fiziksel sorunlara sebep olabilecek durumlara maruz kalabilmelerine neden olmuştur 19. Bu süreçte birçok birey bu durumlardan kaynaklı olarak vücutlarının çeşitli bölümlerinde ağrılar hissetmeye başlamışlardır $(20,21)$. Pandemi öncesinde yapılan farklı araştırmalarda; sigara kullanımının $(22-24)$, kadın cinsiyetin $(25,26)$, masa ve bilgisayar başında kalma sürelerinin $(25,27)$ bireylerin ağrı yaşamalarında etkili olduğu görülmüştür. Ayrıca bireyin uzun süre sosyal etkileşimlerden uzak kalmasının da ağrıyı etkilediği rapor edilmiştir (28). Pandemi öncesinde ağrıyı etkileyebilecek teknoloji başında geçirilen süre faktörünün pandemi ile birlikte artması bireylerin ağrı hissetmelerini artırabilmektedir. Bu araştırmada, bireylerin pandemi döneminde teknoloji kullanımlarından kaynakı ağrı yaşamalarını etkileyebilecek faktörlerden fiziksel aktivite, problemli internet kullanımı ve cinsiyet faktörlerine odaklanılmışır.

Bireylerin yaşayabilecekleri ağrıyı etkileyebilecek faktörlerden birisi olan fiziksel aktivite konusunda alanyazında bir tutarlılık bulunmamaktadır. Fiziksel aktivite ile kas iskelet sistemi rahatsızlıkları arasındaki ilişkiyi ele alan çalışmaların sonuçlarının birbirinden farklılık gösterdiği görülmüştür (29-31). Burada fiziksel aktivitenin varlığından ziyade yoğunluğunun daha önemli bir faktör olarak ele alınabileceği söylenebilir. Çünkü fiziksel aktivitenin çok yoğun $(25,32,33)$ veya zayıf (30) olması bireylerin ağrı yaşamalarına neden olabilirken bireylerin kas iskelet sistemlerine uygun bir fiziksel aktivitenin gerçekleştirilmesinin ağrı açısından koruyucu olabileceği düşünülmektedir (34). COVID-19 pandemisi beraberinde bireylerin fiziksel aktivitelerini olumsuz olarak etkilemiştir $(13,19)$. Türkiye'de üniversite öğrencileriyle yapılan bir araştırmada, katıımcıların \%67.5'inin pandemi döneminde düzenli olarak fiziksel aktivite yapmadığı ve pandemi öncesine göre fiziksel aktivitelerinde önemli düşüşler olduğu görülmüştür (13). Bu durum bireylerin uzun süreli teknoloji kullanımlarıyla birleşince ağrı yaşama sıklıklarının arttığı söylenebilir $(35,36)$. COVID-19 pandemisiyle birlikte bireyler mesleki veya akademik sorumluluklarını ev ortamında teknolojik araçlar ile sürdürmeye başlamışlardır. Dünya'da ve Türkiye'de yapılan farkı araştırmalarda pandemi döneminde bireylerin internet kullanımlarının pandemi öncesine göre artış gösterdiği görülmüştür (37-39). İnternet kullanım oranlarında yaşanan artışlar internetin bilinçsiz, kontrolsüz ve aşııı kullanımını ifade eden bir sorun olan problemli internet kullanım riskini arttırabilmektedir $(10,40,41)$. Araştırmalar, internet kullanım süresinin ve problemli internet kullanımının boyun, sırt, göz ve el bilekleri gibi çeşitli alanlarda ağrı yaşama ile ilişkili olduğunu göstermektedir (42-47). Çünkü problemli internet kullanımı bireylerin internet ile aşırı ve kontrolsüz bir şekilde zaman geçirmesini ifade etmektedir. Bu problemli kullanım esnasında düşük veya yüksek ekran pozisyonu, omuz yükselmesi, belirli bir pozisyonda sürekli olarak durmak ve bu süreçte uygun olmayan postür durumları çeşitli ağrıların yaşanmasına neden olabilmektedir $(44,46,48)$. COVID-19 pandemisiyle birlikte bireylerin internette daha fazla vakit geçirmeleri ve bu süreçte kendilerini 
fiziksel olarak koruyamamaları ağrı yaşamalarına neden olabileceği düşünülmektedir. Bu faktörlere ek olarak pandemi döneminde bireylerin teknoloji kullanımlarından kaynaklı ağrı yaşamalarına etki edebilecek faktörlerden birisinin cinsiyet olabileceği düşünülmektedir. Çünkü kadınların hormonel yapıları ağrılar açısından daha hassas bir konumda yer almalarına neden olmaktadır (49-51). Ayrıca Türk kültürü bağlamında ele alındığında pandemi ile birlikte ev içerisinde kadınların sorumluluklarının büyük oranda artması beraberinde ağrı yaşamalarını artırabileceği düşünülmektedir.

Tüm bunlar değerlendirildiğinde bireylerin pandemi dönemiyle birlikte evde kalarak daha az hareketli bir yaşam içerisinde olmalarının beraberinde getirdiği fiziksel etkilerin incelenmesinin alanyazına katkı sağlayabileceği düşünülmektedir. Dolayısıyla pandemi döneminde bireylerin teknoloji kullanımlarından kaynakıı yaşadıkları ağrıya etki edebilecek faktörlerin ele alınması yürütülecek müdahale yaklaşımlarına destek sunabilecektir. Ayrıca alanyazında kas iskelet sistemi sorunları ile ağrı ve fiziksel aktivite düzeyleri arasında ilişkilerin tutarsızlık göstermesi bu araştırmanın sonuçlarının bu konuda alanyazına katkı sunabileceği düşünülmektedir. Bu kapsamda araştırmada, bireylerin pandemi döneminde teknoloji kullanımlarından kaynaklı ağrı düzeyleri çalışmanın bağımlı değişkeni olarak belirlenmiş bu bağımlı değişkeni açıklayabilecek fiziksel aktivite, problemli internet kullanımı ve cinsiyet gibi faktörler ele alınmıştır. Dolayısıyla bu araştırmanın amacı, COVID-19 pandemisi döneminde bireylerin teknoloji kullanımlarından kaynaklı ağrı düzeylerinin yordayıcıları olarak fiziksel aktivite ve problemli internet kullanım düzeyi ile cinsiyetin rolünü incelemektir.

\section{Yöntem}

Bu araştırma, nicel araştırma yöntemlerinden birisi olan ilişkisel tarama yöntemi ile gerçekleştirilmiştir. ilişskisel tarama modellerinde, iki veya daha fazla değişken arasında birlikte değişimin varlığını ve düzeyini belirlemek amaçlanmaktadır (52). Bu araştırmada, bireylerin teknoloji kullanımlarından kaynaklı ağrı, fiziksel aktivite ve problemli internet kullanımı düzeyleri arasındaki ilişkiler incelendiği ve cinsiyet, fiziksel aktivite ve problemli internet kullanımı faktörlerinin teknoloji kullanımlarından kaynaklı ağrıyı yordayıcı rolü incelendiği için ilişkisel tarama yöntemi kullanılmıştır.

\section{Örneklem}

Araştırmanın örneklem büyüklüğü belirlenirken Şimşek ve arkadaşlarının (53) ev ortamında yaşayan yaşlı bireylerde ağrı ile sağlık durumu, mobilite ve günlük yaşam aktivite düzeyi arasındaki ilişki çalışması göz önünde bulundurulmuştur. Bireylerde ağrının sağlık durumu, mobilite ve günlük yaşam aktiviteleri üzerine etkisi ile ilgili alt bulgularına dayanarak ( $\mathrm{R} 2=.05) 3$ farkı muhtemel determinantla \%5 Tip 1 hata ve \%5 Tip 2 hatada çoklu doğrusal regresyon analizi yapabilmek için en az 249 bireyin dahil edilmesi gerektiği saptandı. Değerlendirmeler çevrimiçi olarak yapıldığından dolayı \%15-\%20 eksik veri intimali göz önünde bulundurularak 296 katılımcı dahil edildi. Bu regresyon modelinde güç analizi "G*Power Software (version 3.1.9.2)" ile yapılmış olup beklenen etki büyüklüğü .052' dir. Daha sonrasında çalışma grubu belirlenirken kolay ulaşılabilir örnekleme yöntemi tercih edilmiştir. Bu örnekleme yönteminde zaman açısından hızlı, maliyeti düşük ve kolay olanı yapma amaçlanmaktadır (52). Bu kapsamda araştırmanın katıımcılarını, Türkiye'de yaşayan 18 yaş üzeri ve aktif internet kullanan 198'i kadın (\%66.9) 98'i erkek olmak üzere (\%33.1) 296 yetişkin birey oluşturmaktadır. Katılımcıların yaş ortalaması 24.27, günlük internet kullanım süreleri ortalaması 6.17 saat ve günlük yürüyüş süreleri ortalaması 36.29 dakika'dır.

\section{İşlem}

Bu araştırmanın planlanmasından raporlaştııımasına kadar ki tüm süreçlerde bilimsel araştırma ve yayın etiği kurallarına bağlı kalınmıştır. Bu kapsamda katıımcılar araştırmaya gönüllülük esası çerçevesinde dahil edilmişlerdir. Araştırmaya katılan katılımcılara araştırma hakkında detaylı bilgi verilmiş ve kendilerinden bilgilendirilmiş onam alınmıştır. Ayrıca Kırşehir Ahi Evran Üniversitesi Tıp Fakültesi Klinik Araştırmalar Etik Kurulu'ndan izin alınmıştır (Karar No:2021-05/49 - Tarih: 09/03/2021). 
Araştırmada; Göktaş ve arkadaşları (54) tarafından Türkçe'ye uyarlanan "Problemli İnternet Kullanımı Ölçeği-Kısa Form-6" ve Öztürk (55) tarafından Türkçe'ye uyarlanan "Uluslararası Fiziksel Aktivite Anketi Kısa Form" kullanılmıştır. Bu ölçme araçlarının araştırma kapsamında kullanımı için ölçekleri uyarlayan yazarlardan izin alınmıştır. Ayrıca araştırmacılar tarafından geliştirilen "Kişisel Bilgi Formu" aracilığıyla araşıırmaya katılan bireylerin teknoloji kullanımlarından kaynaklanan ağrı düzeyleri ve çeşitli sosyodemografik özellikleri belirlenmiştir.

\section{Veri Toplama Araçları}

\section{Problemli İnternet Kullanımı Ölçeği-Kısa Form-6}

Bireylerin öğrencilerinin problemli internet kullanımı düzeylerini belirlemek için Demetrovics ve arkadaşları (56) tarafından geliştirilen ve Göktaş ve arkadaşları (54) tarafından Türkçe'ye uyarlanan "Problemli internet Kullanımı Ölçeği-Kısa Form-6" kullanılmışıı. Ölçme aracı takıntı, inmal ve kontrol bozukluğu olmak üzere 3 alt boyuttan ve 6 maddeden oluşmaktadır. Ölçekten alınabilecek en düşük puan 6 , en yüksek puan ise 30'dur. Ölçekten alınan puanların artması bireylerin problemli internet kullanım düzeylerinin arttığını göstermektedir. Ölçme aracının geçerlik çalışması için yapılan açımlayıcı faktör analizinde üç alt faktörün toplam varyansın \%53.42'sini açıkladığı görülmüştür. Ayrıca ölçme aracının kapsam geçerliliği katsayısı .90 olarak bulunmuştur. Ölçme aracının uyarlama çalışmasında yapılan güvenirlik analizlerinde iç tutarlık katsayısı ve test-tekrar test güvenirlik katsayısı .82 olarak bulunmuştur.

\section{Uluslararası Fiziksel Aktivite Anketi - Kısa Form}

Bireylerin fiziksel aktivite düzeylerini belirlemek için Craig ve arkadaşları (57) tarafından geliştirilen ve Öztürk (55) tarafından Türkçe'ye uyarlanan "Uluslararası Fiziksel Aktivite Anketi - Kısa Form" kullanılmıştır. Bu form bireylerin son yedi gündeki fiziksel aktivitelerini değerlendirmeye yönelik 7 soru bulunmaktadır. Bu sorularda bireylerin oturma, yürüme, orta şiddetli ve şiddetli aktivitelerini belirlemeye yönelik ifadeler bulunmaktadır. Bu anketin toplam puanının hesaplanmasında oturma, yürüme, orta şiddetli ve şiddetli seviyelerine ait belirlenmiş MET ölçümleri toplanarak hesaplanmaktadır. Oturma için MET değeri 1.5, yürüme için 3.3 , orta şiddetli fiziksel aktivite için 4.0 ve şiddetli fiziksel aktivite için 8.0 olarak belirlenmiştir. Anketten alınan puanların artması bireylerin fiziksel olarak daha aktif seviyede olduklarını göstermektedir.

\section{Kişisel Bilgi Formu}

Bireylerin cinsiyet, yaş, günlük internet kullanım süresi, günlük yürüyüş süresi ve teknoloji kullanımlarından kaynaklı ağrı düzeylerini belirlemek için araştırmacılar tarafından oluşturulmuş "Kişisel Bilgi Formu" kullanılmıştır. Bu formda bireylerin sosyo-demografik özelliklerinin yanı sıra teknoloji kullanımlarından kaynakı ağrı düzeylerini belirlemek için 5 'li likert tipinde 5 tane soru yer almaktadır. Bu sorular aracilığıla bireylerin teknoloji kullanımlarını göz önünde bulundurarak göz, boyun, el bilekleri, sırt ve diz bölgelerinde yaşadıkları ağrıları derecelendirmeleri istenmiştir. Katılımcıların bu maddelere verdikleri yanıtlar toplanarak teknoloji kullanımlarından kaynaklı ağı düzeyleri belirlenmiştir. İçerisinde bulunan pandemi döneminden kaynaklı olarak katılımcıların ağrı yaşama durumları yüz yüze ölçülemeyeceği ve hazırlanan bu formun sade ve anlaşlır olmasından kaynaklı olarak böyle bir form hazırlanarak araştırmada kullanılmıştır. Bunlara ek olarak araştırmada katılımcıların ağıı düzeyleri teknoloji özelinde ele alındığı ve geçerlik-güvenirlik çalışması yapılmış ölçme araçlarının genel yaşama ilişkin ağrı düzeyini belirlemeye yönelik olduğu için bu form hazırlanmıştır.

\section{Veri Analizi}

Veri toplama sürecinde ilk olarak ölçekleri kullanmak için gerekli izinler alınmıştır. Daha sonrasında içerisinde bulunan COVID-19 pandemisinden kaynaklı olarak veri toplama işlemi çevrimiçi olarak gerçekleştirilmesi planlanmıştır. Bu kapsamda ölçme aracında yer alan maddeler Google Formlar'a aktarımıştır. Veriler, tek oturumda toplanmıştır. Veriler toplandıktan sonra kendi doldurduğu ölçeğin sonuçlarını öğrenmek isteyen kişilere isterlerse sonuçlarının kendileri ile paylaşılabileceği belirtilmiştir. Bu kapsamda öğrenmek isteyen kişilerle araştırmanın sonunda iletişim kurulmuştur. 
Araştırmanın verileri toplandıktan sonra SPSS paket programına girilmiştir. Daha sonra araştırmanın alt problemlerine bağlı olarak uygun veri analizleri yapılmışı. Illk olarak bireylerin teknoloji kullanımlarından kaynaklı ağrı, fiziksel aktivite ve problemli internet kullanım düzeyleri belirlenmiştir. Daha sonra bireylerin teknoloji kullanımlarından kaynaklı ağrı, fiziksel aktivite ve problemli internet kullanım düzeyleri arasındaki ilişki düzeyini belirlemek için Pearson Momentler Çarpımı Korelasyon Analizi yapılmıştır. Son olarak ise bireylerin cinsiyet, fiziksel aktivite ve problemli internet kullanımı düzeylerinin teknoloji kullanımlarından kaynakı ağrı düzeylerini ne düzeyde yordadığını belirlemek için Çoklu Doğrusal Regresyon Analizi yapılmıştır. Çoklu Doğrusal Regresyon Analizi yapılmadan önce gerekli varsayımlar göz önünde bulundurularak varsayımların karşılanıp karşılanmadığı test edilmiştir. Sonrasında bir kategorik değişken olan cinsiyet değişkenini regresyon analizine dahil edebilmek için dummy (yapay) kodlama yapılarak sayısal hale getirilmiştir.

\section{Bulgular}

Bireylerin COVID-19 pandemisi döneminde teknoloji kullanımından kaynaklı ağrı, fiziksel aktivite ve problemli internet kullanım düzeyleri Tablo 1'de yer almaktadır.

Tablo 1. Bireylerin COVID-19 pandemisi döneminde teknoloji kullanımından kaynaklı ağrı, fiziksel aktivite ve problemli internet kullanım düzeyleri

\begin{tabular}{|c|c|c|c|}
\hline Değisken & $\mathrm{F}$ & $\bar{x}$ & Ss \\
\hline Ağrı & 296 & 13.09 & 4.55 \\
\hline Göz AğrıSı & 296 & 2.78 & 1.17 \\
\hline Boyun Ağrısı & 296 & 2.96 & 1.28 \\
\hline El Bilekleri Ağrısı & 296 & 2.36 & 1.21 \\
\hline Sırt Ağrısı & 296 & 3.18 & 1.30 \\
\hline Diz Ağrısı & 296 & 1.79 & 1.05 \\
\hline Fiziksel Aktivite (MET-dk/hafta) & 296 & 1225.79 & 1917.69 \\
\hline Ağır Aktivite & 296 & 470.75 & 1107.55 \\
\hline Orta Aktivite & 296 & 230.04 & 500.69 \\
\hline Yürüme & 296 & 555.00 & 1003.15 \\
\hline Oturma & 296 & 8.06 & 11.22 \\
\hline Problemli İnternet Kullanımı & 296 & 12.92 & 4.67 \\
\hline
\end{tabular}

Tablo 1 incelendiğinde; bireylerin COVID-19 pandemisi döneminde teknoloji kullanımından kaynaklı ağrı düzeyleri 13.09 (göz ağrısı 2.78; boyun ağrısı 2.96; el bilekleri ağrısı 2.36; sırt ağrısı 3.18; diz ağrısı 1.79), fiziksel aktivite düzeyleri 1225.79 (ağır aktivite 470.75; orta aktivite 230.04; yürüme 555.00; oturma 8.06) ve problemli internet kullanımı düzeyleri 12.92 olduğu görülmektedir.

Bireylerin COVID-19 pandemisi döneminde teknoloji kullanımından kaynaklı ağrı, fiziksel aktivite ve problemli internet kullanımı düzeyleri arasındaki ilişkiyi incelemek için Pearson korelasyon analizi yapılmıştır. Tablo 2'de analiz sonucunda elde edilen bulgular yer almaktadır.

Tablo 2 incelendiğinde; araştırmaya katılan bireylerin COVID-19 pandemisi döneminde teknoloji kullanımından kaynaklı ağrı düzeyleri ile fiziksel aktivite düzeyleri arasında negatif yönde anlamlı bir ilişki bulunmuştur. Ayrıca problemli internet kullanımı düzeyleri ile teknoloji kullanımından kaynaklı ağrı düzeyleri arasında pozitif yönde anlamlı bir ilişki bulunmuştur. Ancak fiziksel aktivite düzeyleri ile problemli internet kullanımı ve teknoloji kullanımından kaynaklı ağ̆ı düzeyleri arasında anlamlı bir ilişki bulunmamıştır. Bu bulgudan yola çıkarak; bireylerin COVID-19 pandemisi döneminde fiziksel aktivite düzeyleri arttıkça teknoloji kullanımından kaynakı ağıı düzeyleri azalacağı söylenebilir. Buna ek olarak problemli internet kullanım düzeyleri arttıkça teknoloji kullanımından kaynakı ağı düzeyleri de artacağı söylenebilir.

Bireylerin COVID-19 pandemisi döneminde cinsiyet, fiziksel aktivite ve problemli internet kullanım düzeylerinin teknoloji kullanımından kaynaklı ağrı düzeylerini ne düzeyde yordadığını belirlemek için çoklu doğrusal regresyon yapıımıştır. Tablo 3'te yapılan analiz sonucunda elde edilen bulgular yer almaktadır. 
Tablo 2. Bireylerin COVID-19 pandemisi döneminde teknoloji kullanımından kaynaklı ağrı, fiziksel aktivite ve problemli internet kullanımı düzeyleri arasındaki ilişki

\begin{tabular}{|l|c|c|c|}
\hline Değ|šken & 1 & 2 & 3 \\
\hline 1.Ağrı & 1 & & \\
\hline 2.Fiziksel Aktivite & $-.124^{\star}$ & 1 & \\
\hline 3.Problemli Internet Kullanımı & $.384^{\star *}$ & .021 & 1 \\
\hline${ }^{*} p<.05 ;$ anlamllık düzeyi ${ }^{\star *} p<.001$; anlamllık düzeyi & & &
\end{tabular}

Tablo 3. Bireylerin COVID-19 pandemisi döneminde teknoloji kullanımından kaynaklı ağrı düzeylerinin yordanmasına ilişkin çoklu doğrusal regresyon analizi sonucu

\begin{tabular}{|c|c|c|c|c|c|c|c|}
\hline Değişken & B & SH $\boldsymbol{\beta}$ & B & $\mathrm{t}$ & $P$ & İkili r & Kısmi r \\
\hline Sabit & 6.470 & 1.105 & & 5.854 & .000 & & \\
\hline Cinsiyet-Kadın & 1.328 & .519 & .138 & 2.562 & .011 & .184 & .148 \\
\hline Fiziksel Aktivite & .000 & .000 & -.110 & -2.056 & .041 & -.124 & -.119 \\
\hline Problemli İnternet Kullanımı & .366 & .052 & .376 & 7.083 & .000 & .384 & .383 \\
\hline $\begin{array}{l}\text { Teknoloji Kullanımından Kaynah } \\
\text { Problemli İternet Kullanımı) + }\end{array}$ & $\begin{array}{l}\text { Ağr }=( \\
170)\end{array}$ & $328 \times$ & & & $x \mathrm{Fiz}$ & & $+(0.366 x$ \\
\hline
\end{tabular}

Araştırmaya katılan bireylerin COVID-19 pandemisi döneminde teknoloji kullanımından kaynakı ağrı düzeyleri üzerinde etkisi olduğu düşünülen cinsiyet, fiziksel aktivite ve problemli internet kullanımı değişkenlerinin, teknoloji kullanımından kaynaklanan ağrıyı ne şekilde yordadığını belirlemek için yapılan Çoklu Doğrusal Regresyon analizi sonucunda; cinsiyet, fiziksel aktivite ve problemli internet kullanımı değişkenlerinin teknoloji kullanımından kaynaklı ağrıdaki toplam varyansın \%18.3'ünü açıkladığı görülmüştür ( $\left.R=.428, R^{2}=.183\right)$. Ayrıca cinsiyet $(p=.011 ; p<.05)$, fiziksel aktivite $(p=.041 ; p<.05)$ ve problemli internet kullanımı $(p=.000 ; p<.05)$ değişkenlerinin teknoloji kullanımından kaynaklı ağrının anlamlı bir yordayıcısı olduğu görülmüştür.

\section{Tartışma}

Ülkemizde kişisel sağlık durumuyla ilgili geniş çalışma gruplarılla yeterince çalışmanın gerçekleştirilmemesi sebebiyle bireylerin sağlık durumlarıyla ilgili bilgiler yeterince net değildir. Bireylerin fiziksel olarak ağrı yaşama eşikleri bireysel farklııklardan etkilenmektedir. Bu araştırmada, bireylerin pandemi döneminde teknoloji kullanımından kaynaklı ağrı düzeylerindeki toplam varyansın \%18.3'ünü anlamlı bir şekilde cinsiyet, fiziksel aktivite ve problemli internet kullanımının açıkladığı görülmüştür. Literatürde yapılan araşıırmalarda, kadınların ağrı açısından erkeklere göre daha hassas bir konumda oldukları görülmüştür $(27,58,59)$. Bizim araştırmamızda da pandemi döneminde kadınların ağrı düzeyleri erkeklere göre anlamlı olarak daha yüksek bulunmuştur. Bu sonuç, kadınların fiziksel yapıları ve toplumsal cinsiyet durumları ile açıklanabilir. Bu durumun hormonel farklııklardan dolayı olduğu savunulmakla beraber kadınların menstural dönemde ağrıya karşı duyarlııklarının değiştiği belirtilmiştir (49-51). Bir görüşe göre östrojen hormonu ağrı duyarılıı̆ını artırmaktadır (49). Buna ek olarak pandemi ile birlikte getirilen kısıllamalar ile evde geçirilen sürenin artması kadınların ev içerisindeki sorumluluklarını artırmıştır. Bu durum fiziksel yapı olarak daha hassas bir konumda olan kadınların erkeklere göre daha fazla ağrı yaşamalarına sebep olabildiği söylenebilir.

Bireylerin ağrı hissetmelerinde etkili olan faktörlerden birisi de fiziksel aktivite durumudur. Özellikle hareketsiz bir yaşamın varlığı $(60,61)$ ve uygun olmayan bir postür (62) bireylerin ağı yaşamalarına neden olabilmektedir. Araştırmada, bireylerin pandemi döneminde teknoloji kullanımından kaynaklı ağıı düzeylerini etkileyen faktörlerden birisinin fiziksel aktivite düzeyleri olduğu görülmüştür. Ayrıca yapılan korelasyon analizinde teknoloji kullanımından kaynaklı ağrı ile fiziksel aktivite düzeyleri arasında negatif yönde düşük anlamlı bir ilişki bulunmuştur. Literatürde yapılan çeşitli araş̧ırmalarda fiziksel aktivite ile kas iskelet sistemi rahatsızıkları arasında ilişki olduğu görülmüştür $(63,64)$. Ayrıca yapılan araştırmalar bireylerin gün içerisindeki fiziksel aktivite düzeylerinin genel sağlık durumlarını açıklamada önemli bir yere sahip olduğunu 
göstermektedir (65). Pandemi dönemiyle birlikte getirilen kısıtlamalar bireylerin fiziksel aktivite gerçekleştirmelerini önemli oranda etkilemiş̧ir. Yapılan araştırmalar, inaktiviteye bağlı olarak sıklıkla bel, sırt ve boyun ağrılarının görülebileceğini göstermektedir $(66,67)$.

COVID-19 pandemisiyle birlikte okullar uzaktan eğitim araçları ile faaliyetlerini sürdürürken, birçok meslek elemanı iş ile ilgili sorumluluklarını ev ortamında teknolojik araçlar ile gerçekleştirmeye başlamışlardır. Ayrıca getirilen sokağa çıkma kısıllamaları ile bireylerin hastalı̆a yakalanmamak için evlerinde kalmaları teknolojik araçlarla daha fazla etkileşim kurmalarına yol açmıştır. Bu durum beraberinde çeșitli sorunları ortaya çıkarabilmektedir. Çünkü kullanım süresinin artması ve bireylerin internet kullanımlarını kontrol etmekte zorluklar yaşamaları fiziksel, psikolojik ve sosyal olarak çeşitli zorluklar yaşamalarına neden olabilmektedir (9). Araştırmada, bireylerin pandemi döneminde teknoloji kullanımından kaynakı ağrı düzeylerindeki toplam varyansın çok önemli bir kısmını problemli internet kullanımı düzeylerinin açıkladığı görülmüştür. Bireylerin internet ve teknolojik araçlar başında fazla zaman geçirmeleri çeşitli fiziksel sorunlar yaşamalarına neden olabilmektedir $(68,69)$. Son yıllarda yapılan çalışmalarda uzun süre bilgisayar başında vakit geçirenlerin kas iskelet rahatsızığı geçirme riskinin yüksek olduğu saptanmıştır $(70,71)$. Ayrıca internet kullanım süresinin ve problemli internet kullanımının bireylerin vücutlarının farklı bölümlerinde ağrılar hissetmelerine yol açabileceği birçok araştırmada desteklenmiştir $(42,43,45,46)$. NUDATA çalışmasında ise katıımcıların haftada 15-20 saati aşkın fare kullanımının gergin boyun sendromu riskini artırdığı görülmüştür (72). Karlqvist günde 2 saat çalışanlarda, Yun ise günde 6-9 saat çalışanlarda üst ekstremite mesleki kas iskelet rahatsızlıklarının fazla görüldüğünü saptamışlardır (73-75). Jimker ve arkadaşları bu alanda yapılan farklı 9 araştırmayı değerlendirmişler ve bu çalışmalarda masa başında geçirilen süre ile mesleki kas-iskelet rahatsızlıkları arasında ilişki olduğunu belirtmişlerdir (75). Bir çalışmada yeni işe başlayan 632 kişi 3 yll izlenmiş, işe başladıktan sonraki ilk yıl içinde çalışanların yarısından çoğunda üst ekstremite problemlerinin olduğu saptanmıştır (76).

Bu araştırma sahip olduğu çeşitli özellikler kapsamında sınırlıık göstermektedir. Araştırma, Türkiye'de 18 yaş ve üzeri internet kullanıcısı olan 296 yetişkin birey ile sınırıdır. Ayrıca katılımcıların çoğunluğunun kadın olması ve cinsiyet açısından sayısal anlamda birbirine yakın sayıların olmaması bir başka sınılılıktır. Çünkü araştırmada cinsiyet bireylerin teknoloji kullanımından kaynaklı ağrı düzeylerini etkileyebilecek bir faktör olarak ele alınmıştır. Bunlara ek olarak araştırmadan elde edilen sonuçlar bireylerin teknoloji kullanımından kaynaklı ağrı, fiziksel aktivite ve problemli internet kullanımı düzeylerini belirlemek için kullanılan ölçme araçlarının ölçtüğü nitelikler ile sınırlıık göstermektedir. Bu araştırmada, bireylerin teknoloji kullanımından kaynaklı ağrı düzeylerini belirlemek için araştırmacılar tarafından bir form oluşturulmuş ve 5'li likert tipinde hazırlanmış bu form aracıı̆̆ıla bireylerin ağrı düzeyleri incelenmiştir. Bu kapsamda geçerlik ve güvenirlik çalışması yapıımış geniş kapsamlı bir ağrı düzeyini belirleyecek ölçme aracı kullanılmamıştır. Araştırmadaki bir başka sınırlılık ise verilerin toplanma biçimidir. Veriler içerisinde bulunan pandemi durumundan kaynaklı olarak çevrimiçi olarak toplanmıştır. Dolayısıyla katılımcıların ölçme aracında yer alan maddelere ilişkin anlayamadıkları yerleri araşıımacılara soramamaları gönüllülerin ölçme aracını tam olarak anlayıp doğru şekilde doldurmalarını engellemiş olabilir.

Araştırmadan elde edilen sonuçlar ve sınırlııklar çerçevesinde çeşitli önerilerde bulunulabilir. Araştırmada, COVID-19 pandemisi döneminde bireylerin teknoloji kullanımından kaynaklı ağrı düzeylerine etki edebilecek faktörlerden bazılarının cinsiyet, fiziksel aktivite ve problemli internet kullanımı olduğu görülmüştür. Bu faktörler haricinde başka faktörlerinde teknoloji kullanımından kaynaklı ağrı düzeyine etki edebileceği düşünülmektedir. Dolayısıyla yapılacak araştırmalarda pandemi döneminde bireylerin teknoloji kullanımından kaynakı ağrı düzeylerine etki edebilecek farklı faktörler ele alınabilir. Araştırmada, katılımcılar çok farklı yaş gruplarındaki bireylerden seçilmiştir. Yapılacak farklı araştırmalarda daha özel gruplarla (üniversite öğrencileri, sağlık çalışanları vb.) ile yapılabilecek araştırmaların literatüre katkı sağlayabileceği düşünülmektedir. Araştırmada, bireylerin teknoloji kullanımından kaynaklı ağıı düzeylerine etki edebilecek faktörlerden birisinin fiziksel aktivite düzeyi olduğu göz önünde bulundurulduğunda bu süreçte bireylerin ev içerisinde veya dışarıda maske-mesafe ve hijyen kurallarına uyarak fiziksel aktiviteler gerçekleştirmelerine yönelik farkındalık oluşturacak medya içeriklerinin veya fiziksel aktivite programlarının oluşturulabileceği söylenebilir. Araştırmada, bireylerin teknoloji kullanımından kaynakıı ağrı düzeylerine etki 
edebilecek faktörlerden birisinin problemli internet kullanımı düzeyi olduğu göz önünde bulundurulduğunda bireylerin pandemi döneminde internet ve teknolojiyi sağlıklı bir şekilde kullanabilmelerine yönelik farkındalık oluşturacak medya içeriklerinin veya eğitim programlarının düzenlenebileceği söylenebilir. Pandemi döneminde fiziksel aktivitenin kısıllanmasıyla birlikte teknoloji karşısında geçirilen sürelerin gerek iş kaynaklı gerek başka sebeplerden ötürü normal döneme göre daha uzun olması ister istemez kaçınılmazdır. Bu noktada masa başında uzun süreli hareketsiz ve yanlış postürde kalmanın vücut üzerindeki etkilerini minimale indirmek adına kişilerin masa başı düzenine dikkat etmesi için fizyoterapistler tarafından çeşitli video ve görsel içerikler ile bilinçlendirme çalışmaları yürütülebilir.

Sonuç olarak bu araştırmada, COVID-19 pandemisi döneminde bireylerin teknoloji kullanımından kaynaklı ağıı düzeylerinin yordayıcıları olarak fiziksel aktivite ve problemli internet kullanım düzeyi ile cinsiyetin rolü incelenmiştir. Araştırmada, fiziksel aktivite ve problemli internet kullanım düzeyi ile cinsiyet faktörlerinin pandemi döneminde bireylerin teknoloji kullanımından kaynakı ağrı düzeylerini açıklamada önemli bir yere sahip olduğu görülmüştür. Özellikle pandemi dönemiyle birlikte ev içerisinde geçirilen sürenin artması ve bu sürenin inaktif olarak geçirilmesi ağrı yaşamaya sebep olabilmektedir. Ayrıca pandemi döneminde internet kullanım sürelerinin artması ve beraberinde problemli bir kullanımın oluşması göz, boyun, sırt ve baş gibi çeşitli bölgelerde ağrılara yol açabilmektedir. Bunlara ek olarak kadınların fiziksel yapıları açısından ağrı yaşamaya daha hassas bir konumda yer almaları ve pandemi ile birlikte kadınların ev içerisindeki rollerinin artması ağı yaşamalarında bir etkiye sahip olabilmektedir. Bu sonuçlar pandemi döneminde fiziksel aktivitenin ve internetin sağlıkı bir şekilde kullanımının fiziksel sağlık açısından önemli bir role sahip olduğunu göstermektedir.

\section{Kaynaklar}

1. World Health Organization. WHO director-general's opening remarks at the media briefing on COVID-19. https://www.who.int/director-general/speeches/detail/who-director-general-s-opening-remarks-at-the-mediabriefing-on-covid-19---11-march-2020 (20 Nisan 2021'de ulaşıldı).

2. T.C. Sağlık Bakanlığı. COVID-19 bilgilendirme Sayfası. https://covid19.saglik.gov.tr/ (6 Nisan 2021 'de ulaşıldı).

3. Bostan S, Erdem R, Öztürk YE, Kllıc T, YIImaz A. The effect of COVID-19 pandemic on the Turkish society. Electron J Gen Med 2020; 17(6): em237.

4. Liang L, Ren H, Cao R, et al. The effect of COVID-19 on youth mental health. Psychiatric Quarterly 2020; 91(3): 841-852.

5. Al Zubayer A, Rahman ME, Islam MB, et al. Psychological states of Bangladeshi people four months after the COVID-19 pandemic: An online survey. Heliyon. 2020; 6(9): e05057.

6. Chen RN, Liang SW, Peng Y, et al. Mental health status and change in living rhythms among college students in China during the COVID-19 pandemic: A large-scale survey. J Psychosom Res 2020; 137: 110219.

7. Planchuelo-Gómez Á, Odriozola-González P, Irurtia MJ, de Luis-García R. Longitudinal evaluation of the psychological impact of the COVID-19 crisis in Spain. J Affect Disord 2020; 277: 842-849.

8. El Keshky MES, Alsabban AM, Basyouni SS. The psychological and social impacts on personal stress for residents quarantined for COVID-19 in Saudi Arabia. Arch Psychiatr Nurs 2021; 35(3): 311-316.

9. Baltacı Ö, Akbulut ÖF, Zafer R. COVID-19 pandemisinde problemli internet kullanımı: Bir nitel araştırma. Kırşehir Ahi Evran Üniversitesi Sağlık Bilim Enstitüsü Dergisi 2020; 1(3): 126-140.

10. Sun Y, Li Y, Bao Y, et al. Brief report: increased addictive internet and substance use behavior during the COVID-19 pandemic in China. Am J Addict 2020; 29(4): 268-270.

11. Pausé C, Parker G, Gray L. Resisting the problematisation of fatness in COVID-19: In pursuit of health justice. Int J Disaster Risk Reduct 2021; 54: 102021.

12. Tar E, Atik D. Pandemi döneminde obezite riski. Diyabet, Obezite ve Hipertansiyonda Hemşirelik Forumu Dergisi 2020; 12(2): 37-41.

13. Erdoğan R. Pandemi döneminde beden eğitimi ve spor yüksekokulu öğrencilerinin beslenme alıskanlıkları ve fiziksel aktivite düzeylerinin belirlenmesi. OPUS Uluslararası Toplum Araştırmaları Dergisi 2021; 17: 145-164.

14. Moawad RA. Online learning during the COVID-19 pandemic and academic stress in university students. Revista Românească pentru Educație Multidimensională 2020; 12(1): 100-107.

15. Chandra Y. Online education during COVID-19: perception of academic stress and emotional intelligence coping strategies among college students. Asian Education and Development Studies 2020; 10(2): 229-238. 


\section{Bağımlılık Dergisi - Journal of Dependence}

16. Akbulut ÖF. Üniversite öğrencilerinin pandemi döneminde kariyer streslerinin COVID-19 korkusu, kişilik özellikleri ve çeşitli sosyo-demografik değişkenler sçısından incelenmesi. FSMVU Eğitim Araştırmaları Kongresi, 2021.

17. Autin KL, Blustein DL, Ali SR, Garriott PO. Career development impacts of COVID-19: Practice and policy recommendations. Journal of Career Development 2020; 47(5): 487-494.

18. Mahmud MS, Talukder MU, Rahman SM. Does 'Fear of COVID-19'trigger future career anxiety? An empirical investigation considering depression from COVID-19 as a mediator. Int J Soc Psychiatry 2020; 2: 1-11.

19. Tison GH, Avram R, Kuhar P, et al. Worldwide effect of COVID-19 on physical activity: a descriptive study. Ann Intern Med 2020; 173(9): 767-770.

20. El-Tallawy SN, Nalamasu R, Pergolizzi J V., Gharibo C. Pain management during the COVID-19 pandemic. Pain Ther 2020; 9: 453-466.

21. Shanthanna H, Strand NH, Provenzano DA, et al. Caring for patients with pain during the COVID-19 pandemic: consensus recommendations from an international expert panel. Anaesthesia 2020; 75(7): 935-944.

22. Mathews JA, Mills SB, Jenkins VM, Grimes SM, Morkel MJ, Mathews W et al. Back pain and sciatica: controlled trials of manipulation, traction, sclerosant and epidural injections. Br J Rheumatol 1987; 26(6): 416423.

23. Altınel L. Profesyonel hastane çalışanlarında bel ağrısı ve bel ağrısını etkileyen faktörler. Tıp Araştırmaları Dergisi 2007; 5(3): 115-120.

24. Altınel L, Kose KC, Ergan V, et al. The prevalence of low back pain and risk factors among adult population in Afyon region, Turkey. Acta Orthop Traumatol Turc 2008; 42(5): 328-333.

25. Balague F, Troussier B, Salminen JJ. Non-specific low back pain in children and adolescents: risk factors. Eur Spine J 1999; 8(6): 429-438.

26. Bedson J, Mottram S, Thomas E, Peat G. Knee pain and osteoarthritis in the general population: what influences patients to consult? Fam Pract 2007; 24(5): 443-453.

27. Shuval K, Donchin M. Prevalence of upper extremity musculoskeletal symptoms and ergonomic risk factors at a Hi-Tech company in Israel. Int J Ind Ergon 2005; 35(6): 569-581.

28. Xavier FMF, Ferraz MPT, Marc N, et al. Elderly people's definition of quality of life. Braz J Psychiatry 2003; 25(1): 31-39.

29. Briggs AM, Straker LM, Bear NL, Smith AJ. Neck/shoulder pain in adolescents is not related to the level or nature of self-reported physical activity or type of sedentary activity in an Australian pregnancy cohort. BMC Musculoskelet Disord 2009; 10: 87.

30. Holth HS, Werpen HKB, Zwart JA, Hagen K. Physical inactivity is associated with chronic musculoskeletal complaints 11 years later: Results from the Nord-Trøndelag Health Study. BMC Musculoskelet Disord 2008; 9: 159.

31. Morken T, Magerøy N, Moen BE. Physical activity is associated with a low prevalence of musculoskeletal disorders in the Royal Norwegian Navy: A cross sectional study. BMC Musculoskelet Disord 2007; 8: 56.

32. Vikat A, Rimpelä M, Salminen JJ, Rimpelä A, Savolainen A, Virtanen SM. Neck or shoulder pain and low back pain in Finnish adolescents. Scand J Public Health Suppl 2000; 28(3): 164-173.

33. Tesarz J, Schuster AK, Hartmann M, Gerhardt A, Eich W. Pain perception in athletes compared to normally active controls: A systematic review with meta-analysis. Pain 2012; 153: 1253-1262.

34. Can S, Arslan E, Ersöz, G. Güncel bakış açısı ile fiziksel aktivite. SPORMETRE Beden Eğitimi ve Spor Bilim Dergisi 2014; 12(1): 1-10.

35. Adedoyin RA, Idowu BO, Adagunodo RE, Owoyomi AA, Idowu PA. Musculoskeletal pain associated with the use of computer systems in Nigeria. Technology and Health Care 2005; 13(2): 125-130.

36. Harris C, Straker L, Pollock C, Smith A. Children, computer exposure and musculoskeletal outcomes: The development of pathway models for school and home computerrelated musculoskeletal outcomes. Ergonomics 2015; 58(10): 1611-1623.

37. Özdemir D, Arpacıoğlu S. Sosyal medya kullanımı, sağık algısı ve sağlık arama davranışının koronavirüs korkusu üzerine etkisi. Psikiyatride Güncel Yaklaşımlar 2020; 12(1): 1-15.

38. Islam MS, Sujan MSH, Tasnim R, et al. Problematic internet use among young and adult population in Bangladesh: Correlates with lifestyle and online activities during the COVID-19 pandemic. Addict Behav Rep 2020; $12: 100311$.

39. Statista. Coronavirus: impact on online usage in the U.S. - Statistics \& Facts. https://www.statista.com/topics/6241/coronavirus-impact-on-online-usage-in-the-us/ (30 Nisan 2021'de ulaşıldı). 
40. Baltacı Ö, Akbulut ÖF, YıImaz E. Problemli internet kullanımında güncel bir risk faktörü: COVID-19 pandemisi. Humanistic Perspective 2021; 3(1): 97-121.

41. Duan $L$, Shao $X$, Wang $Y$, et al. An investigation of mental health status of children and adolescents in china during the outbreak of COVID-19. J Affect Disord 2020; 275: 112-118.

42. Kelley KJ, Gruber EM. Problematic Internet use and physical health. J Behav Addict 2013; 2(2): 108-112.

43. Dol KS. Fatigue and pain related to Internet usage among university students. J Phys Ther Sci 2016; 28(4): 1233-1237.

44. Hakala PT, Rimpelä AH, Saarni LA, Salminen JJ. Frequent computer-related activities increase the risk of neckshoulder and low back pain in adolescents. Eur J Public Health 2006; 16(5): 536-541.

45. Burke A, Peper E. Cumulative trauma disorder risk for children using computer products: results of a pilot investigation with a student convenience sample. Public Health Rep 2002; 117(4): 350-357.

46. Yang G, Cao J, Li Y, et al. Association between internet addiction and the risk of musculoskeletal pain in Chinese college freshmen - a cross-sectional study. Front Psychol 2019; 10: 1959.

47. Koca TT, Berk E. Influence of internet addiction on academic, sportive, and recreative activities in adolescents. J Public Health 2019; 27(4): 531-536.

48. Jacobs K, Baker NA. The association between children's computer use and musculoskeletal discomfort. Work 2002; 18(3): 221-226.

49. Fillingim RB, Edwards RR, Powell T. The relationship of sex and clinical pain to experimental pain responses. Pain 1999; 83(3): 419-425.

50. Fillingim RB, Ness TJ. Sex-related hormonal influences on pain and analgesic responses. Neurosci Biobehav Rev 2000; 24(4): 485-501.

51. Özçaka Ö, Biçakçi N, Köse T. Effect of the menstrual cycle on pain experience associated with periodontal therapy: Randomized, pilot study. J Clin Periodontol 2005; 32(11): 1170-1174.

52. Büyüköztürk Ş, Klıç Çakmak E, Akgün ÖE, et al. Eğitimde Bilimsel Araştırma Yöntemleri. Ankara: Pegem, 2018.

53. Şimşek TT, Yumin ET, Öztürk A, et al Ev ortamında yaşayan yaşıl bireylerde ağrı ile sağlık durumu, mobilite ve günlük yaşam aktivite düzeyi arasındaki ilişki. Turk J Phys Med Rehabil 2011; 57(4): 216-2020.

54. Göktaş S, Aygar H, Akbulut Zencirci S, et al. Problematic internet use questionairre-short form-6 (PIUQ-SF 6): a validity and reliability study in Turkey. Int J Res Med Sci 2018; 6(7): 2354-2360.

55. Öztürk M. Üniversitede eğitim-ögretim gören öğrencilerde uluslararası fiziksel aktivite anketinin geçerliligi ve güvenirliği ve fiziksel aktivite düzeylerinin belirlenmesi.Yüksek Lisans Tezi, Ankara: Hacettepe Üniversitesi Sağllk Bilimleri Enstitüsü, 2005.

56. Demetrovics Z, Király O, Koronczai B, et al. Psychometric properties of the Problematic Internet Use Questionnaire Short-Form (PIUQ-SF-6) in a nationally representative sample of adolescents. PLoS One 2016; 11(8): e0159409.

57. Craig CL, Marshall AL, Sjöström M, et al. International physical activity questionnaire: 12-country reliability and validity. Med Sci Sports Exerc 2003; 35(8): 1381-1395.

58. Karlqvist L, Toomingas A, Hagberg M, et al. Self-reported working conditions of VDU operators and associations with musculoskeletal symptoms: a cross-sectional study focusing on gender differences. Int J Ind Ergon 2002; 30(4-5): 277-294.

59. Fillingim RB, King $C D$, Ribeiro-Dasilva $M C$, et al. Sex, gender, and pain: A review of recent clinical and experimental findings. J Pain 2009; 10(5): 447-485.

60. Esen H, Fığlalı N. Çalışma duruşu analiz yöntemleri ve çalıșma duruşunun kas-iskelet sistemi rahatsızıklarına etkileri. Sakarya University Journal of Science 2013; 17(1): 41-51.

61. Önen Tekin H. Ofis çalişanlarinda fiziksel aktivite düzeyinin kas iskelet sistemi rahatsizliklarina etkisì. Yüksek Lisans Tezi, Diyarbakır: Dicle Üniversitesi Sağlık Bilimleri Enstitüsü, 2018.

62. Delisle A, Larivière C, Plamondon A, Imbeau D. Comparison of three computer office workstations offering forearm support: Impact on upper limb posture and muscle activation. Ergonomics 2006; 49(2): 139-160.

63. Morken T, Magerøy N, Moen BE. Physical activity is associated with a low prevalence of musculoskeletal disorders in the Royal Norwegian Navy: A cross sectional study. BMC Musculoskelet Disord 2007; 8: 56.

64. Holth HS, Werpen HKB, Zwart JA, Hagen K. Physical inactivity is associated with chronic musculoskeletal complaints 11 years later: Results from the Nord-Trøndelag Health Study. BMC Musculoskelet Disord 2008; 9: 159.

65. Haskell WL, Lee IM, Pate RR, et al. Physical activity and public health: Updated recommendation for adults from the American College of Sports Medicine and the American Heart Association. Circulation 2007; 116(9): 10811093. 


\section{Bağımlılık Dergisi - Journal of Dependence}

66. Uz Tunçay S, Yeldan I. Is physical inactivity associated with musculoskeletal disorders? Agri 2013; 25(4): 147155.

67. Kuru T, Yelan I, Zengin A, et al. Erişkinlerde ağrı ve farkli ağrı tedavilerinin prevalansi. Ağrı 2011; 23(1): 22-27.

68. Eliacik K, Bolat N, Koçyiğit $\mathrm{C}$, et al. Internet addiction, sleep and health-related life quality among obese individuals: a comparison study of the growing problems in adolescent health. Eat Weight Disord 2016; 21(4): 709-717.

69. Kee IK, Byun JS, Jung JK, Choi JK. The presence of altered craniocervical posture and mobility in smartphoneaddicted teenagers with temporomandibular disorders. J Phys Ther Sci 2016; 28(2): 339-346.

70. Bilgin E. Bilgisayar kullanımı ile ilişkili boyun ve üst ekstremite rahatsızıkları. STED Dergisi 2017; 26(6): 251247.

71. Gün I, Özer A, Ekinci E, Öztürk A. Bilgisayarla çalışan kişilerin ifade ettikleri sağlık sorunları ve bilgisayar kullanım özellikleri. Erciyes Tıp Dergisi 2004; 26(4): 153-157.

72. Moom RK, Sing LP, Moom N. Prevalence of musculoskeletal disorder among computer bank office employees in Punjab (India): A Case Study. Procedia Manuf 2015; 3: 6624-6631.

73. Güneş G. Bilgi ve belge merkezleri çalışanlarının iş ortamından kaynaklanan sağlık şikayetleri ve risk faktörleri. Doktora Tezi, İstanbul: Marmara Üniversitesi Türkiyat Araştırmaları Enstitüsü, 2009.

74. Nang $\mathrm{H}$, Harfield $\mathrm{A}$. The nature of technology consumption among school children in lower northern Thailand. International of Interactive Mobile Technologies 2019; 13(5): 137-146.

75. IJmker S, Huysmans MA, Blatter BM, et al. Should office workers spend fewer hours at their computer? A systematic review of the literature. Occup Environ Med 2007; 64(4): 211-222.

76. Gerr F, Marcus M, Ensor C, et al. A prospective study of computer users: I. Study design and incidence of musculoskeletal symptoms and disorders. Am J Ind Med 2002; 41(4): 221-235.. 